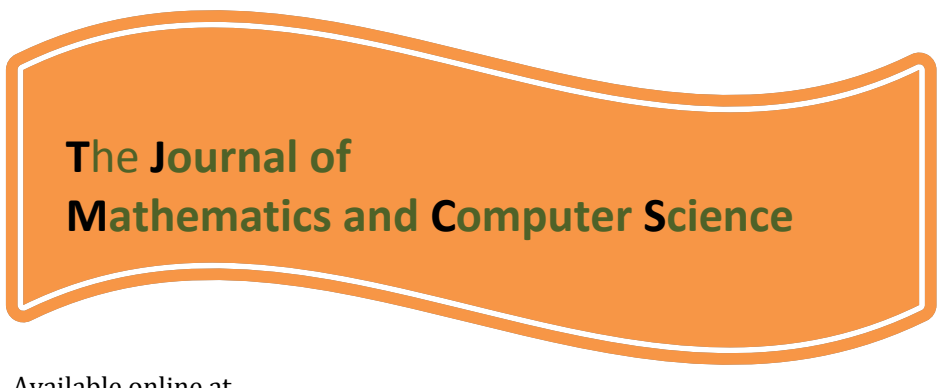

http://www.TJMCS.com

The Journal of Mathematics and Computer Science Vol. 4 No.3 (2012) 463 - 472

\title{
Numerical Modelling of End-Plate Moment Connection Subjected to Bending and Axial Forces
}

\author{
Mahmoud Baei1 ${ }^{*}$, Mehdi Ghassemieh ${ }^{2}$, Alireza Goudarzi ${ }^{3}$ \\ 1, 2,3 3 chool of Civil Engineering, University of Tehran \\ 1m.baei@ut.ac.ir \\ 2mghassem@ut.ac.ir \\ 3a.goudarzi@ut.ac.ir
}

Received: February 2012, Revised: May 2012

Online Publication: July 2012

\begin{abstract}
Steel beam-to-column joints are often subjected to a combination of bending and axial forces. The level of axial forces in the joint may be significant, typical of pitched-roof portal frames, sway frames or frames with incomplete floors. An approach, based on finite element modelling, is presented in order to numerically investigate the seismic performance of bolted steel end-plate moment connection by including the effect of axial forces in the connection. Current specifications for steel joints do not take into account the presence of axial forces (tension and/or compression) in the joints. A single empirical limitation of $10 \%$ of the beam's plastic axial capacity is the only enforced provision in Annex J of Eurocode 3.The methods for applying loads to the connection were considered to be only monotonic loadings. For the nonlinear finite element analysis the modelling process was carried out using ABAQUS computer program. The results of the finite element analysis of the connection showed that by applying the tensile axial load of the beam into the connection the ultimate bending capacity of the connection will decrease. Finally, it reveals that the presence of an axial force on the beam significantly modifies the joint response.
\end{abstract}

Keywords: End-Plate Moment Connection, Nonlinear Finite Element, Bending Moment and Axial Force

\footnotetext{
1,* Corresponding author: Graduate student of Structural Engineering

${ }^{2}$ Associate Professor, Structural Engineering

${ }^{3}$ Graduate student of Structural Engineering
} 


\section{Introduction}

Bolted steel connections, such as T-stubs and end-plate connections, can be visualized as assemblages of components (plates, bolts, and welds). Because of the large variety of connection configurations possible, many geometrical discontinuities and associated stress concentrations present in bolted connections. Also presence of frictional forces that lead to nonlinear phenomena such as slip and the need to model uplift and contact forces that lead to prying action, then these connections exhibit an overall nonlinear structural behaviour commonly classified as "semi-rigid".

Bolted end-plate connections are extensively used for connecting beams to columns or beams to beams in multi-storey steel frame buildings. These connections are divided into two categories: flush end-plate and extended end-plate. The typical uses of end-plate moment connections are illustrated in Fig. 1.1. There are two major types of end-plate connections: flush, as shown in Fig. 1.2. and extended, as shown in Fig. 1.3.

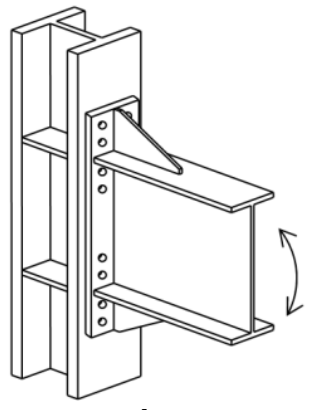

(a) Beam-to-column connection

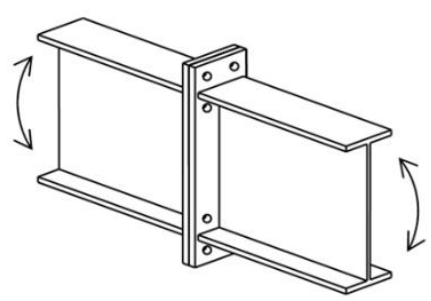

(b) Beam splice connection

Figure 1.1. Typical uses for end-plate moment connections

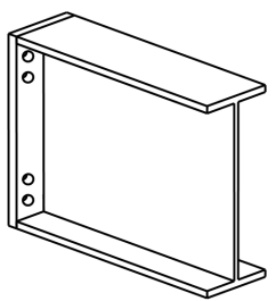

(a) Unstiffened

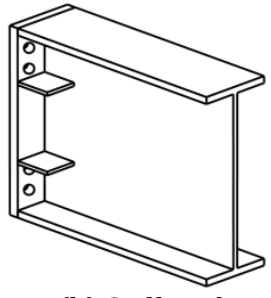

(b) Stiffened

Figure 1.2. Flush end-plate connections

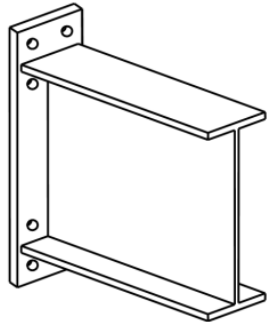

(a) Unstiffened

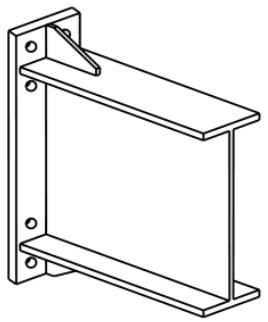

(b) Stiffened

Figure 1.3. Extended end-plate connections

The most important structural properties of the joints that should be known prior to the analysis of frame structure and the design of its members are the moment resistance, rotational stiffness, and rotation capacity. Eurocode 3 [1] contains design rules for determining the properties of several types of connections including the bolted flush end-plate. Beam-to-column joints are often subjected to a combination of bending and axial forces. Although in many ordinary building frames the level of axial 
force coming from the beam and/or slab is usually low, it can reach significant values in many instances; such as: ordinary type sway frames subjected to significant horizontal loading (seismic or extreme wind loads); frames subjected to gravity or horizontal loading, and pitched roof portal frames. Besides the number of influencing parameters affecting the overall behaviour, the prying forces developed at the interface of column flange and end-plate intensifies the problem of understanding the behaviour. The application of the axial force in the endplate moment connection along with the existence of the bending moment due to gravity loads as well as lateral loads can result in altering the behaviour of the entire connection. Finite element method of analysis is an ideal tool to solve such a complicated problem.

In recent years, number of research program have been conducted to study the prediction of the behaviour of beam-to- column joints under bending only and without axial force. Kukreti et al. [2], Bahaari and Sherbourne [3], Bose et al. [4] and Abolmaali et al. [5] have employed finite element method to analyze end-plate joints subjected to monotonic loading. Broderick et al. [6] investigated the response of flush end-plate joints under earthquake loading. da Silva et al. [7] have proposed analytical expressions for the full non-linear response of a beam-to-column joint under combined bending and axial force. Shi et al. [8] developed a tee-stub model based on beam and yield line theory for flush and extended end-plate joints. de Lima et al. [9] experimentally investigated the behavior of extended endplate beam to column joints subjected to bending and axial force. The results show that the presence of an axial force on the connection significantly modifies the joint response. Fanning et al. [10] presented an ANSYS finite element model for flush end-plate joints. In this paper, the effect of axial forces on the behavior of endplate moment connection is investigated using the ABAQUS computer program. All the nonlinear properties such as material, contact, large deformation, and buckling are included in the FE model. To evaluate the accuracy of FE models for end-plate bolted connections, the numerical results are compared with experimental results were tested by da Silva et al. [7] and de Lima et al. [9]. Also the failure mode of different components of the connection is investigated.

\section{Finite element modelling}

\subsection{Type of Elements, Contact, Boundary Condition and Loading Process}

The modelling is investigated with finite element ABAQUS computer program. For finite element modelling, three-dimensional solid elements have been employed to model end-plate, beam, column, and the bolts. This element is an eight-node element with three translational degrees of freedom at each node (C3D8). Between the end-plate and column surface as well as the surface between the bolts surfaces with end-plate and column, contact elements are utilized with friction coefficient of 0.3. The nodes near the support located at the top and bottom section of column are restrained in all directions. The analyses is consist of 3 steps: First the bolts are pretentioned with temperature so as to produce the pretentional stress of $550 \mathrm{MPa}$ in each bolt, then the axial loading applied as a tensile or compression load and finally the lateral loading is applied as a displacement type loading to the beam tip. General views of the mesh pattern for the connection detail as well as the entire bolt used in the modelling configuration are shown in Fig. 2.1.

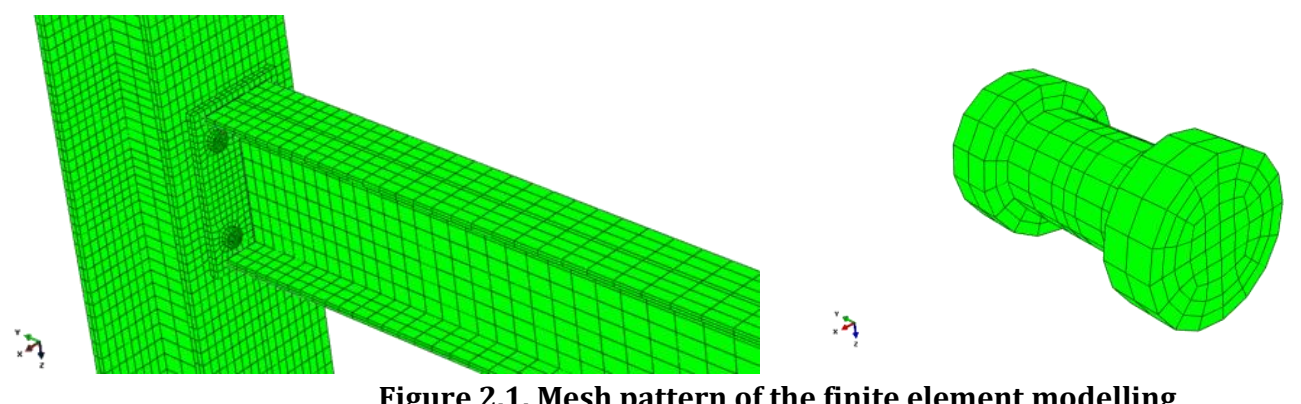

Figure 2.1. Mesh pattern of the finite element modelling 


\subsection{Nonlinear Material Properties}

Steel is a ductile material that exhibits nonlinear material properties caused by plastic yielding and strain hardening. This behaviour of steel has been imposed to the model by introducing two different stress-strain diagrams for beam, column, and end-plate materials and bolt material. The stress-strain relationship for all connection components is represented using a multi-linear model in Fig. 2.2.

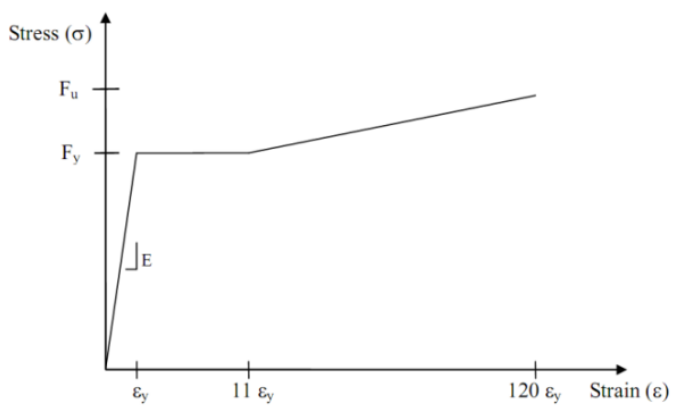

Stress-strain diagram for steel beam, column and end-plate

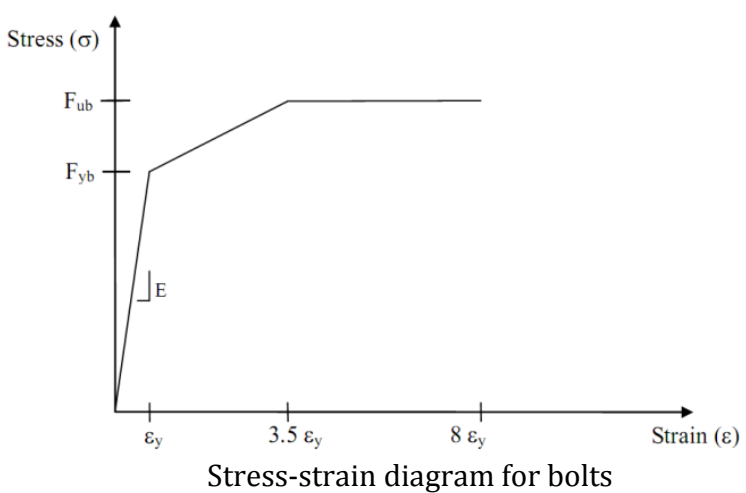

Figure 2.2. Stress-strain diagram for components

\subsection{Test Case Chosen for Calibration of the Numerical Model}

Several specimens of end-plate moment connections have been tested subjected to monotonic loading by da Silva et al. (on flush end-plate (FE1-FE9)) [7] and de Lima et al. (on extended end-plate (EE1-EE7)) [9]. In this research, for investigating the effect of bending and axial forces on an end-plate moment connection several models are implemented. The models are presented in Table 2.1. In order to calibrate the numerical models, FE6 model was used as benchmark case of the study that was tested previously by da Silva et al. [7]. FE6 model is subjected to bending forces and axial compressive loading with $27 \% \mathrm{Npl}$ (beam's plastic axial capacity). The specimen's geometrical characteristics that were used are shown respectively in Fig. 2.3. and material properties are tabulated in Table 2.2.

Table 2.1. Finite Element Models

\begin{tabular}{|l|c|c|}
\hline \multicolumn{2}{|l}{ Model } & $\begin{array}{c}\text { Axial force } \\
(\mathrm{kN})\end{array}$ \\
\hline \multirow{4}{*}{ Flush end-plate } & FE1-NUM (M only) & - \\
\cline { 2 - 3 } & FE5-NUM (N=-20\% Npl) & -265.0 \\
\cline { 2 - 3 } & FE6-NUM (N=-27\% Npl) & -345.0 \\
\cline { 2 - 3 } & FE-NUM (N=-35\% Npl) & 463.75 \\
\hline \multirow{5}{*}{ Extended end-plate } & FE9-NUM (N=+20\% Npl) & 265 \\
\cline { 2 - 3 } & EE1-NUM (M only) & -135.6 \\
\cline { 2 - 3 } & EE2-NUM (N=-10\% Npl) & -265.0 \\
\cline { 2 - 3 } & EE3-NUM (N=-20\% Npl) & 135.6 \\
\cline { 2 - 3 } & EE6-NUM (N=+10\% Npl) & 265.0 \\
\hline
\end{tabular}




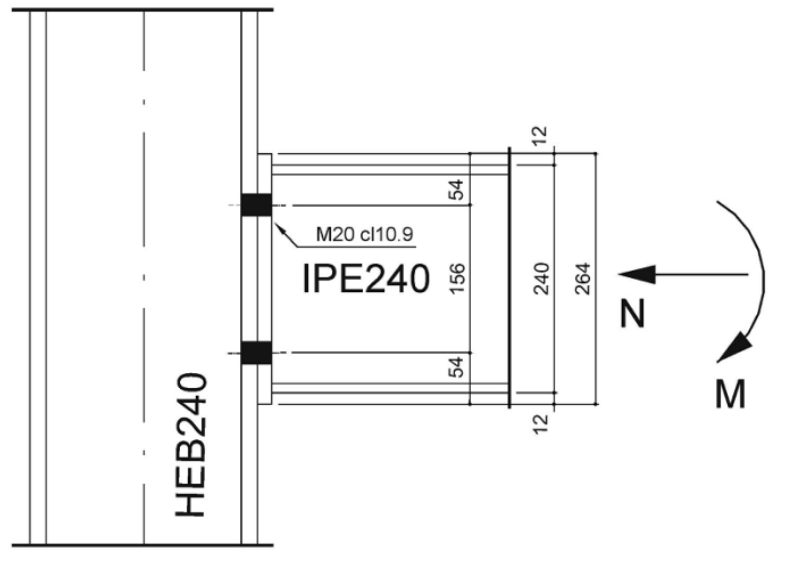

Figure. 2.3. Typical end-plate, beam and geometry

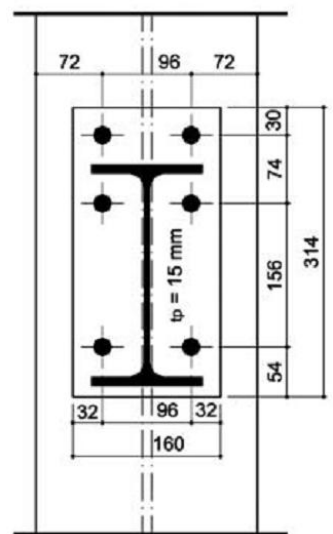

Extended end-plate [9]

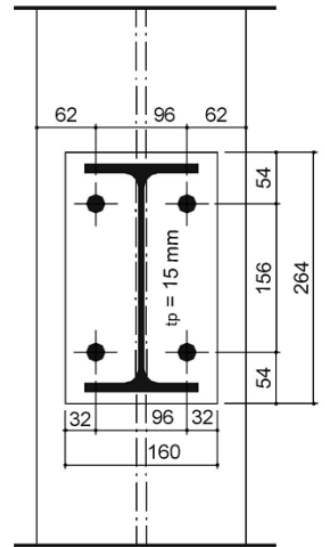

Flush end-plate [7]

Table 2.2. Material Properties

\begin{tabular}{|c|c|c|c|c|}
\hline Material & Application & Yielding stress (MPa) & Ultimate stress (MPa) & Young's modulus (MPa) \\
\hline Steel grade S275 & Beam web & 363.4 & 454.3 & 203,713 \\
\hline Steel grade S275 & Beam flange & 340.14 & 448.23 & 215,222 \\
\hline Steel grade S275 & Column web & 372.02 & 477.29 & 206,936 \\
\hline Steel grade S275 & Column flange & 342.95 & 448.79 & 220,792 \\
\hline Steel grade S275 & End-plate & 369.44 & 503.45 & 200,248 \\
\hline M20 & Bolts & 900 & 1000 & 200,000 \\
\hline
\end{tabular}

The moment versus rotation curve for both experimental and numerical modelling for FE6 are shown in Fig. 2.4. Also Figs. 2.5. and 2.6. present the graphical deformations of beam bottom flange buckling obtained from numerical analysis as well as experiment and deformation at the top of the endplate. As shown, the deformations predicted by finite element method are almost identical to the deformations visualized in experiments.

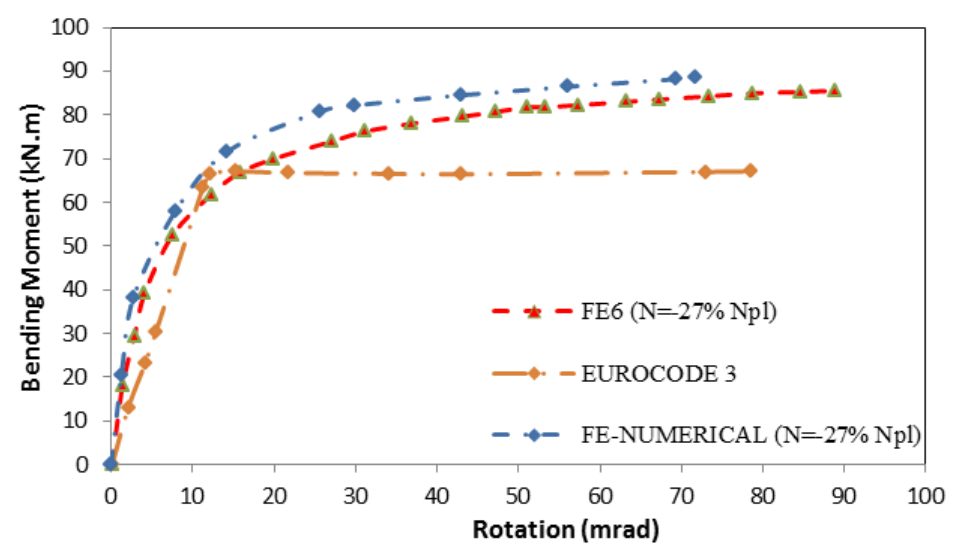

Figure 2.4. Moment vs. rotation curve for FE6 


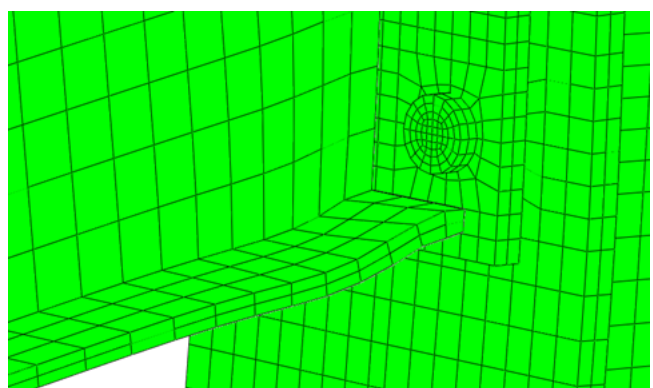

(a) Numerical

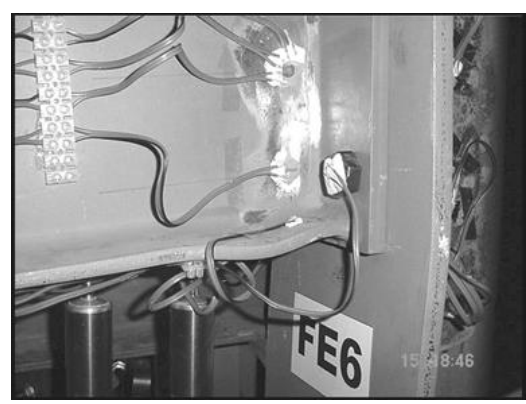

(b) Experimental

Figure 2.5. Bottom flange buckling

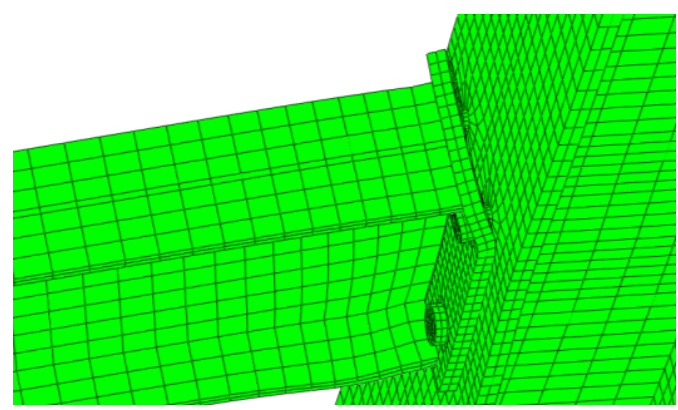

(a) Numerical

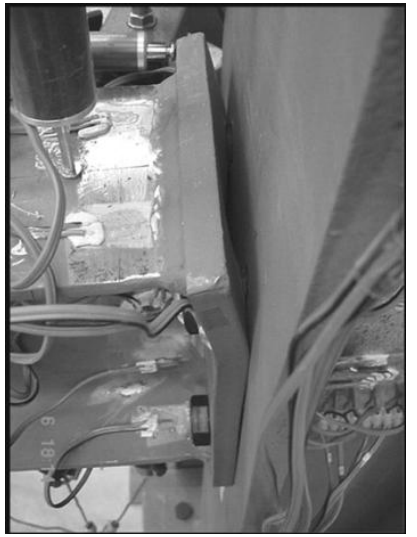

(b) Experimental

Figure 2.6. Deformation of top of end-plate

As shown in the above figures, the numerical results have good correlations with the experimental results.

\subsection{Failure Modes}

The three main failure modes for a bolted end-plate connection proposed by Eurocode 3 [1] are considered in this study and they are illustrated in Fig. 2.7. These modes are defined, as follows:

Mode 1: plastic hinges form at the bolt-line and at the beam web

Mode 2: plastic hinges form at the beam web followed by yielding of the bolts

Mode 3: yielding of the bolts only while the end-plate remains elastic

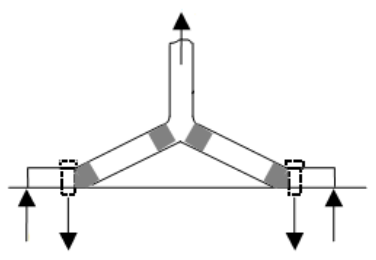

(a) Mode 1

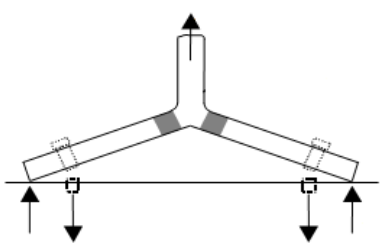

(b) Mode 2

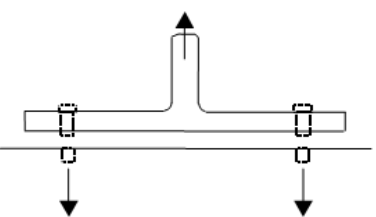

(c) Mode 3

Figure 2.7. Failure modes for a bolted end-plate connections (Eurocode 3) 


\section{Finite Element Results}

The moment vs. rotation curves from finite element modelling for the FE1, FE5, FE6, FE9, FE-NUM (with 35\% Npl) and for Eurocode 3 are all presented in Fig. 3.1.

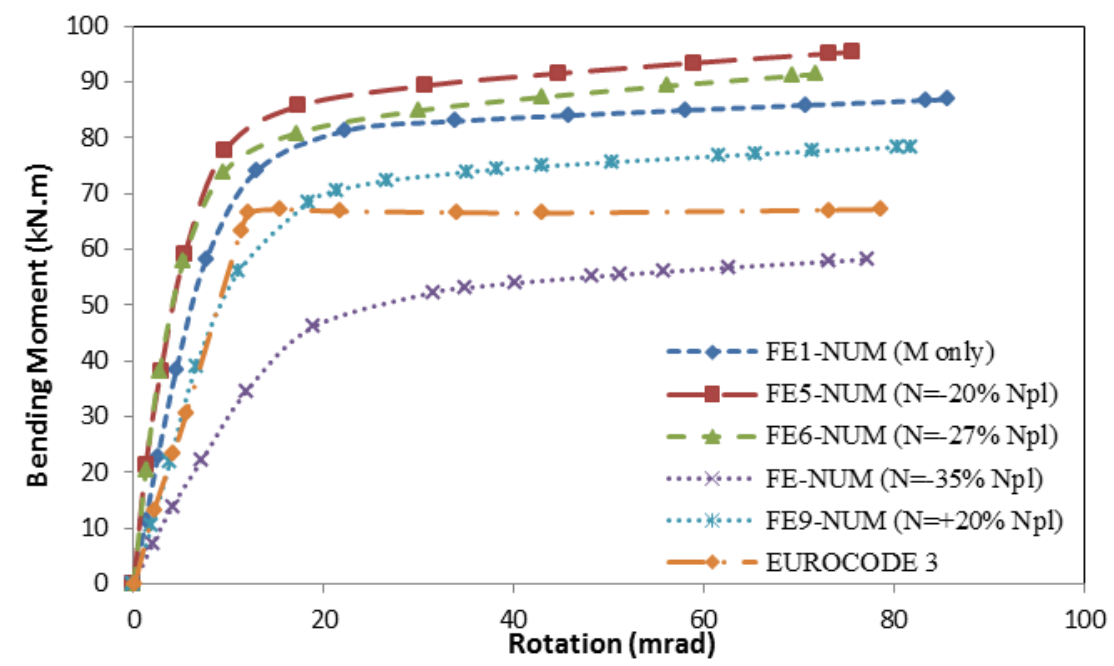

Figure 3.1. Moment vs. rotation curves of the finite element models for flush endplate

The finite element modelling of moment vs. rotation curves for the EE1, EE2, EE3, EE6, EE7 and for Eurocode 3 are all specimens are also illustrated in Fig. 3.2.

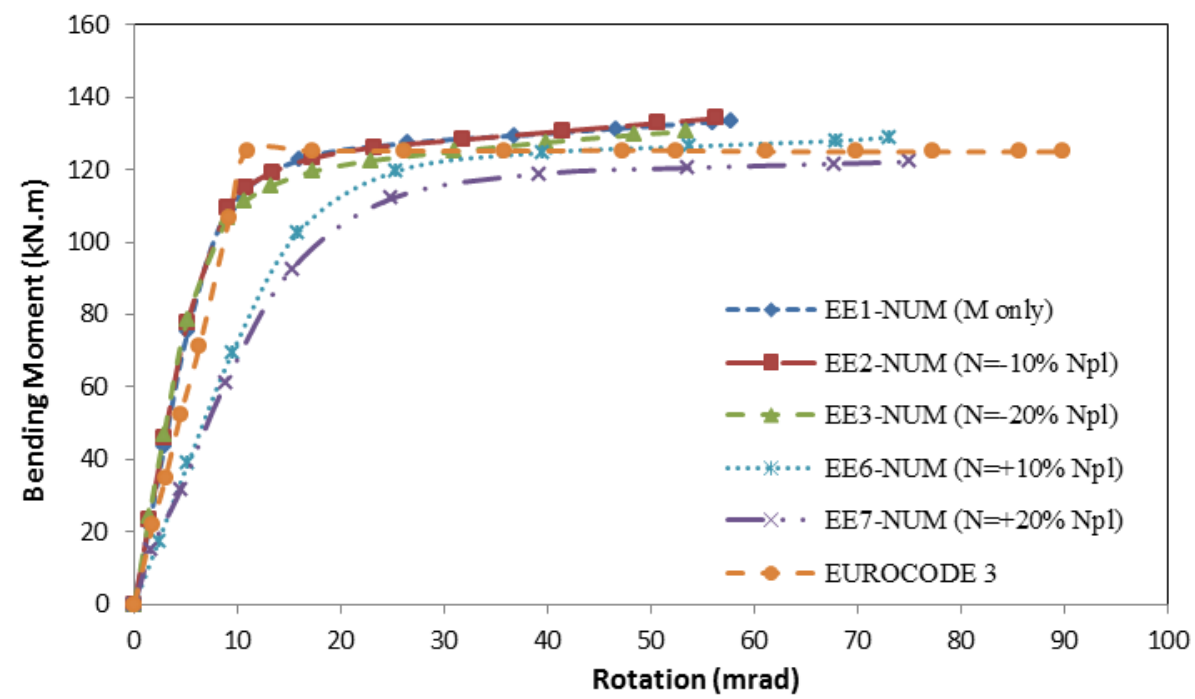

Figure 3.2. Moment vs. rotation curves of the finite element models for extended end-

plate

Some of the findings and observations drawn from the two figures are as follows. With certain level of compressive axial forces along with bending moment the capacity of the connections may increase to some extent. As shown in Fig.3.1. It may be observed that for flush end-plate with $20 \%$ axial compressive forces of the axial beam plastic resistance with the bending moment, the ultimate moment will be reached 
and beyond $20 \%$ of the compressive forces the ultimate moment reduces due to excessive deformations which results in beam flange buckling. Results obtained from numerical model FE-NUM with 35\% axial compressive forces of the beam plastic resistance show the flange beam bucking and the moment deterioration. Also for a level of $27 \%$ axial compressive forces of the beam plastic resistance, the ultimate bending moment becomes almost similar to the case with moment only and without any axial forces applied. The application of axial tensile force along with the bending moment in the connection results in decreasing of the bending resistance of the joint. The axial tensile force along with the moment forces reduces the overall capacity of the connection. Also, as shown in Fig.3.2. for the extended end-plate the with $10 \%$ axial compressive forces of the axial beam plastic resistance with the bending moment, the ultimate moment will be reached and beyond $10 \%$ of the compressive forces the ultimate moment reduces and application of axial tensile force along with the bending moment in the connection results in decreasing of the bending resistance of the joint. As expected, by applying the axial forces in to the connection, the bending moment behaviour was changed. The axial tensile force along with the moment forces reduces the overall capacity of the connection.

Table 3.1 shows experimental values presented by da Silva et al. [7] and de Lima et al. [9] along with results obtained from finite element method. Parameters like bending moment resistance as well as initial stiffness are the quantities that are compared and illustrated in the table. As shown, the numerical results are relatively close to the experimental values.

Table 3.1. Experimental Values vs. Finite Element Results

\begin{tabular}{|c|c|c|c|c|c|c|c|}
\hline \multirow[t]{2}{*}{ Test Specimen } & \multirow{2}{*}{$\begin{array}{l}\text { Axial force } \\
\quad(\mathrm{kN})\end{array}$} & \multicolumn{2}{|c|}{$\begin{array}{c}\text { Connection flexural resistance } \\
\text { (kN.m) }\end{array}$} & \multirow[t]{2}{*}{ Difference(\%) } & \multicolumn{2}{|c|}{$\begin{array}{c}\text { Connection initial stiffness } \\
(\mathrm{kN} \cdot \mathrm{m} / \mathrm{rad})\end{array}$} & \multirow[t]{2}{*}{ Difference(\%) } \\
\hline & & FE Model & Experimental & & FE Model & Experimental & \\
\hline FE1 (M only) & - & 76.6 & 68.4 & 11.9883 & 7361 & 7244 & 1.61513 \\
\hline FE5 $(\mathrm{N}=-20 \% \mathrm{Npl})$ & -265.0 & 81.6 & 78.5 & 3.949045 & 11038 & 10610 & 4.03393 \\
\hline FE6 $(\mathrm{N}=-27 \% \mathrm{Npl})$ & -345.0 & 77.2 & 72.4 & 6.629834 & 11065 & 9927 & 11.46368 \\
\hline FE9 $(\mathrm{N}=+20 \% \mathrm{Npl})$ & 264.9 & 62.11 & 52.3 & 18.75717 & 5961 & 9084 & 34.37913 \\
\hline EE1 (M only) & - & 122.72 & 118.7 & 3.386689 & 15038 & 20290 & 25.88467 \\
\hline EE2 $(\mathrm{N}=-10 \% \mathrm{Npl})$ & -135.6 & 132.84 & 125.4 & 5.933014 & 15808 & 15685 & 0.784189 \\
\hline EE3 $(\mathrm{N}=-20 \% \mathrm{Npl})$ & -265.0 & 127.51 & 118.1 & 7.967824 & 16389 & 16228 & 0.992112 \\
\hline EE6 $(\mathrm{N}=+10 \% \mathrm{Npl})$ & 135.6 & 119.61 & 111.5 & 7.273543 & 12692 & 13060 & 2.817764 \\
\hline EE7 $(\mathrm{N}=+20 \% \mathrm{Npl})$ & 265.0 & 112.03 & 101.5 & 10.37438 & 14959 & 14905 & 0.362295 \\
\hline
\end{tabular}

Von-mises stress contours as well as contour of plastic strain equivalent (PEEQ) are shown for the overall finite element modelling and bolts at the end time step of the analysis for the FE6 specimen; respectively in Figs. 3.3 and 3.4. 

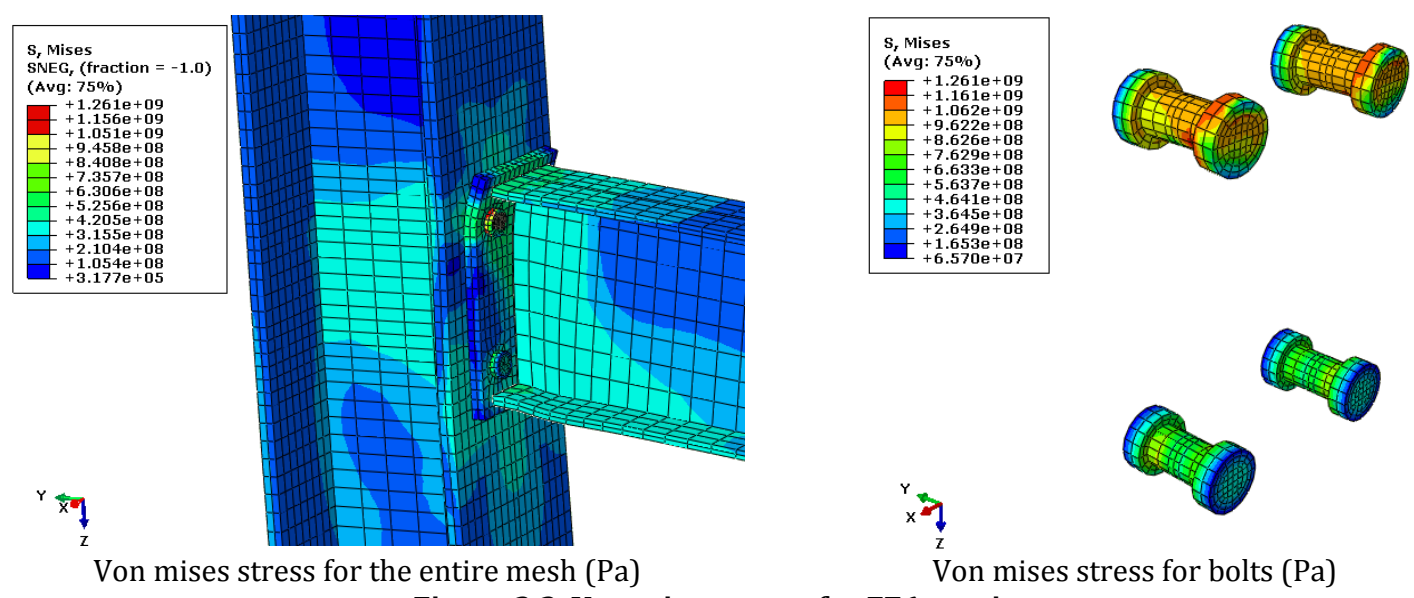

Figure 3.3. Von mises stress for FE6 specimen
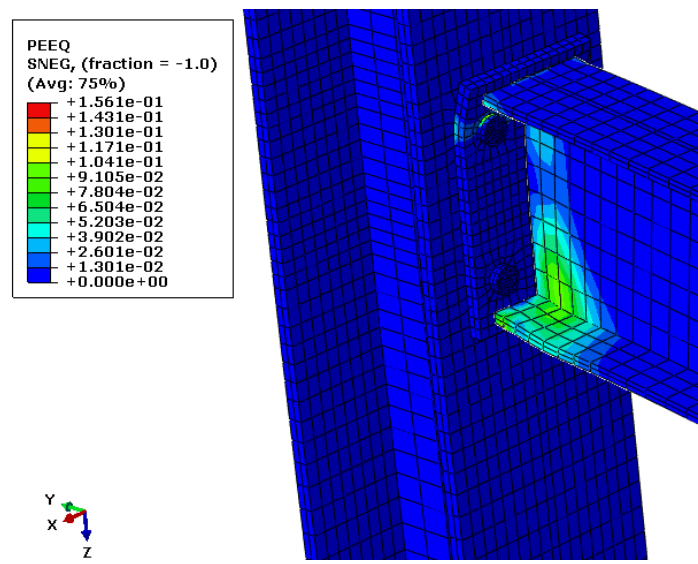

PEEQ for the entire mesh
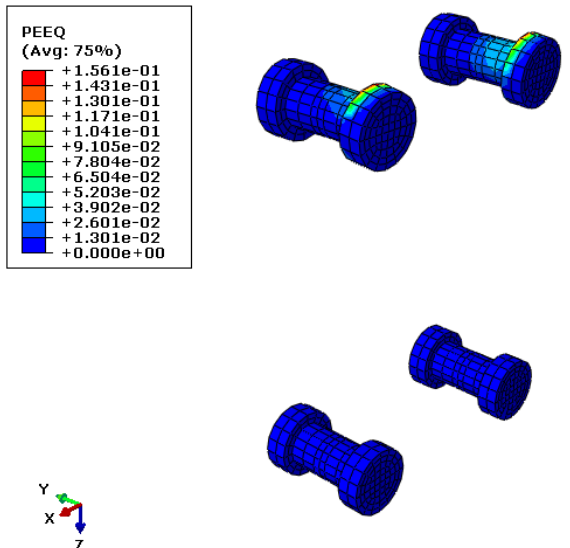

PEEQ stress for bolts

Figure 3.4. PEEQ for FE6 specimen

The results from finite element method emphasize that since the tensile bolts may control connection failure so for tensile force in these models mode 3 is the main failure mode. In case, the compressive axial force is applied along with bending moments, connection moment capacity is initially increased by increasing the axial force and after a while the beam flange buckling may take place and therefore for these models the main failure mode is considered to be mode 2 which means that plastic hinge forms at the beam web followed by yielding of the bolt.

\section{Conclusion}

In this study, a finite element model is introduced in order to study the behaviour of end-plate moment connection subjected to bending as well as axial forces. Characteristics of the connection indicate that the results obtained from the numerical model and analysis by the finite element method is in close agreement with the test results. An increase of the moment resistance was noted for compressive axial force below $25 \%$ and $10 \%$ of the beam axial plastic resistance respectively for flush end-plate and extended end-plate. Beyond this point, flange buckling was observed in all of the compressive axial with bending moment load combinations. It means that by increasing compressive axial force, initially the moment capacity increases but in continue, the moment capacity decreases due to occurrence of different failure mode in type of beam flange bulking. The modes of failure that exist in connection and were suggested by Eurocode 3 are predicted very well by the finite element model. 
The results obtained from this study suggests that it is needed to review the current $10 \%$ limitation considered by Eurocode 3 for flush end-plate moment connection subject to bending moment and axial forces. Thus in the case of the end-plate moment connection subjected to bending moments along with the axial forces, the influence of axial force must definitely be considered on assessment of ultimate moment capacity of connection.

\section{References}

[1] Eurocode 3, ENV-1993-1-1:1992/A2, Annex J, Design of steel structures-joints in building frames. CEN, European Committee for Standardisation, Document CEN/TC 250/SC 3, Brussels, 1998.

[2] Kukrete, A.R., Ghassemieh, M. and Murray, T.M., "Behaviour and design of large-capacity moment end plates," Journal of Structural Engineering, Vol. 116, NO. 3, pp. 809-828, 1990.

[3] Bahaari, M.R. and Sherbourne, A.N., "Computer modelling of an end-plate bolted connection," Journal of Computer and Structure, Vol 52, No. 5, PP. 879-893, 1994.

[4] Bose, B., Wang, Z.M. and Sarkar, S., "Finite-element analysis of unstiffened flush end-plate bolted joints," Journal of Structural Engineering, Vol. 123, pp. 1614-1621, 1997.

[5] Abolmaali, A., Matthys, J.H., Farooqi, M., and Choi, Y., "Development of moment-rotation model equations for flush end-plate connections," Journal of Constructional Steel Research, Vol. 61, No. 12, pp. 1595-1612, 2005.

[6] Broderick, B.M. and Thomson, A.W., "The response of flush end-plate joints under earthquake loading," Journal of Constructional steel research, Vol. 58, No. 9, pp. 1161-1175, 2002.

[7] da Silva, L., Lima, L., Vellasco, P. and Andrade, S., and S. A. L. de Andrade, "Behaviour of flush end-plate beam-tocolumn joints under bending and axial force," Steel and Composite Structures, Vol. 4, No. 2, pp. 77-94, 2004.

[8] Shi, Y.J., Chan, S.L. and Wong, Y.L., "Modelling for moment-rotation characteristics for end-plate connections," Journal of Structural Engineering, Vol. 122, NO. 6, pp. 1300-1306, 1996.

[9] de Lima, L., Simões da Silva, L., Vellasco, P. and Andrade, S., "Experimental evaluation of extended endplate beamto-column joints subjected to bending and axial force," Engineering Structures, Vol. 26, No. 10, pp. 1333-1347, 2004. [10] Fanning, P., Tucker, M., and Broderick, B.M, "Non-linear finite element analysis of semi-rigid bolted end-plate connections", Proceedings of the Fifth International Conference on Computational Structures Technology, pp. 397403, 2000. 